УДК 547.922

\title{
ФЛАВОНОИДЫ POLYGONUM HETEROPHYLLUM LINDM.
}

\author{
(C) Э.Н. Джафарова ${ }^{1 *}$, С.В. Серкеров ${ }^{2}$, Л.А. Мустафаева ${ }^{2}$
}

${ }^{1}$ Институт генетических ресурсов НАН Азербайджана, пр. Азадлыट, 155, Баку, AZ1106 (Республика Азербайджан), e-mail: eldar_novruzov@yahoo.co.uk ${ }^{2}$ Институт ботаники НАН Азербайджана, Бадамдарское шоссе, 40, Баку, AZ1073 (Республика Азербайджан)

Виды горца Polygonum L. богаты различными биологически активными веществами - флавоноиды, катехины, антрахиноны, стильбены и др. Виды рода горец характеризуются высоким содержанием флавоноидных веществ, которые обладают антиоксидантыми, антимикробными, противовирусными, антиаллергическими, антиканцерогенными, противоспалительными свойствами. Исследованы качественный состав и количественное содержание флавоноидов надземной части Polygonum heterophyllum. Методом двумерной бумажной хроматографии установлено, что экстракт из надземной части растений содержит 11 соединений полифенольной природы, 7 веществ дают характерную реакцию на флавоноиды. Методом препаративной хроматографии на бумаге в индивидуальном состоянии выделены два вещества, колоночной хроматографией на полиамиде - три вещества, два из которых являются агликонами, а три - гликозидами. На основании хроматографических и спектральных данных агликоны идентифицированы как кверцетин и лютеолин. По результатам кислотного гидролиза, а также хроматографических и спектральных данных гликозиды идентифицированы как лютеолин-7-глюкозид, кверцетин-3-галактозид и кверцетин-3-арабинозид. Установлено, что в зависимости от местопроизрастания растений содержание флавоноидов изменяется в пределах 1,44-2,12\% на воздушно-сухой вес сырья.

Ключевые слова: Polygonum heterophyllum, флавоноиды, надземная часть, хроматография, спектроскопия, гидролиз.

\section{Введение}

Род горец Polygonum L. сем. Polygonaceae Juss. обьединяет 300 видов. Из них на Кавказе произрастают 39, а в Азербайджане 29 видов [1]. Виды этого рода широко используются в народной и научной медицине при лечении ряда заболеваний $[2,3]$. Некоторые из них являются официальными лекарственными растениями ряда государств. Широкий спектр лечебных действий видов Polygonum L. связан с их химическим составом, особенно флавоноидными соединениями. Виды рода Polygonum L. характеризуются содержанием флавоноидов, таннинов, сесквитерпенов, антрахинонов, стильбенов [4-6]. Виды рода Polygonum L. обладают широким спектром фармакологических действий: гастропротекторной [7], противовирусной [8], антибактериальной [9], гепатопротекторный [10], нейропротекторной [11], антиаллергической [12], противовоспалительной [13], антиоксидантной и антиканцерогенной [14] активностью. Некоторые флавоноиды обладают потенциальным ингибиторным действием на определенные ферментативные системы, активизируя протеинтирозинкиназы, протеинкиназы С, фосфолиазы и др. Эти свойства доказывают, что флавоноиды могут способствовать укреплению здоровья, профилактике заболеваний, а растения, содержащие их, могут быть использованы в качестве потенциального лекарственного сырья.

Виды рода Polygonum L., произрастающих в Азербайджане, в химическом отношении мало исследованы. Целью данной работы является исследование качественного состава и количественного содержания флавоноидов горца разнолистного (P. heterophyllum Lindm.).

Джафарова Эльнура Эльдар гызы - научный сотрудник, e-mail: eldar_novruzov@yahoo.co.uk Серкеров Сираджеддин Вели огль - главный научный сотрудник, e-mail: s.serkerov@gmail.ru Мустафаева Латафат Ахад гызы - ведущий научный сотрудник, e-mail: s.serkerov@gmail.ru

\section{Материалы и методы исследования}

Материалом исследования служили надземные части горца разнолистного Polygonum heterophyllum, собранные в окрестностях села Амсар Ку-

\footnotetext{
* Автор, с которым следует вести переписку.
} 
бинского района Азербайджанской Республики (14 июля 2015 г.) в период цветения. Воздушно-сухую надземную часть растения (1,5 кг) экстрагировали $95 \%$ этанолом методом мацерации с последующим нагреванием $70-80^{\circ} \mathrm{C}$. Экстракт отфильтровали, упаривали под вакуумом до густого остатка и добавляли воду. Водный раствор последовательно обрабатывали сначала гексаном, а затем системой гексан - этилацетат $(1: 9)$ и $н$-бутанолом. Гексан-этилацетатные фракции упаривали в вакууме. Остаток растворяли в этаноле и осаждали хлороформом. Качественный состав суммы флавоноидов исследовали методом одно- и двумерной хроматографии на бумаге Filtrak (FN-16) в следующих системах раствортелей: I - н-бутанол - уксусная кислота - вода (4:1:2), II - уксусная кислота - вода (15:85), III - 2\% уксусная кислота, IV - $н$-бутанол этилацетат - вода ( $2: 9: 2)$ (для гликозидов), $\mathrm{V}$ - уксусная кислота - муравьиная кислота (3:2) (для агликонов), VI - $н$-бутанол - уксусная кислота - вода (4: $1: 5)$ верхняя фаза, VII - $\mu$-буганол - пиридин - вода $(4: 2: 2)$ (для сахаров). Хроматограммы просматривали в видимом и УФ-свете до и после воздействия парами аммиака, $5 \%$ раствором хлорида алюминия в этаноле, $1 \%$ раствором хлорида железа $[15,16]$, сахара проявляли анилинфталатом [17]. Индивидуальные флавоноиды получали путем хроматографирования на колонке с полиамидом «Wolem». Элюацию проводили водой, водным спиртом с возрастающим количеством последнего, смесью спирта с хлороформом и подокисленной уксусной кислотой.

Конфигурацию гликозидных связей и величину окисных циклов углеводной части и строение флавоноидов установили по результатам полных, частичных кислотных, ферментативных гидролизов, щелочной деструкции и по данным УФ-спектров $[15,16]$, УФ-спектры снимали в спектрофотометре Spekol 1500. Суммарное содержание флавоноидов определяли спектрометрическим методом [18]. Расчет содержания флавоноидов вычисляли в пересчете на авикулярин.

\section{Результаты и обсуждение}

В результате двумерной хроматографии на бумаге в системах I и II в первичном спиртовом экстракте установлено наличие 11 соединений, из которых 7 дают характерную реакцию на флавоноиды. По величине и плотности пятен основными соединениями в сумме флавоноидов из надземной части горца разнолистного являются вещества, представленные пятнами $3,5,6,9,10$. Эти пятна в УФ-свете флуоресцируют темно-коричневым цветом. При действии 5\% хлористым алюминием пятна 5, 6, 9 флуоресцируют различными оттенками.

Препаративной хроматографией на бумаге из эфирного извлечения выделяли два индивидуальных вещества. Из этилацетат-гексановой фракции при хроматографии на колонке с полиамидом выделили пять веществ, обозначенные как вещества А, Б, В, Г, Д, которые после трехкратной кристаллизации в метаноле и хроматографирования на бумаге в различных системах растворителей дали неизменные пятна, что свидетельствует об их индивидуальности. На основании пробы по Брианту [19] вещества А, Б были отнесены к агликонам, а вещества В, Г, Д- к гликозидам.

Вещество A - желтые игольчатые кристаллы, легко растворимые в этаноле, метаноле, ацетоне, слабо в эфире, не растворимы в гексане, хлороформе и воде, $\mathrm{R}_{\mathrm{f}}(0,33$ и 0,39$)$ в системах I и $\mathrm{V}$, соответственно. Окраска на хроматограмме в УФ-свете желтая, при обработке спиртовым раствором $\mathrm{AlCl}_{3}$ приобретает ярко-желтую окраску. В УФ-спектре $\lambda_{\max } 258,300,370$ нм, в этаноле добавлением $\mathrm{CH}_{3} \mathrm{COONa} 273,375$ нм; этанол $+\mathrm{CH}_{3} \mathrm{COONa}+\mathrm{H}_{3} \mathrm{BO}_{3}-260,385$ нм; этанол $+\mathrm{AlCl}_{3}: 270,420$ нм; этанол $+\mathrm{AlCl}_{3}+\mathrm{HCl}: 265,430$ нм; этанол $+\mathrm{C}_{2} \mathrm{H}_{5} \mathrm{ONa}: 250,320$ нм. Сдвиги, которые проявляются при добавлении ионизирующих и комплексообразующих реагентов, указывают на наличие свободных гидроксильных групп в положениях $\mathrm{C}_{3}, \mathrm{C}_{5}, \mathrm{C}_{7}$, $\mathrm{C}_{3}{ }^{\prime}, \mathrm{C}_{4}^{\prime}$ [15]. При щелочной деструкции вещество $\mathbf{A}$ образует флороглюцин и протокатехиновую кислоту, что доказывает идентичность вещества А с 3,5,7,3',4'-пентагидроксифлавоном (кверцетин).

Вещество Б - светло-желтые игольчатые кристаллы, легко растворимые в этаноле, метаноле, ацетоне, слабо в эфире, в УФ-спектре (этанола, $\lambda_{\max }$ ) 260, 272, 355; этанол $+\mathrm{CH}_{3} \mathrm{COONa:} \mathrm{272,} \mathrm{368;} \mathrm{этанол} \mathrm{+}$ $\mathrm{H}_{3} \mathrm{CO}_{3}: 272,356$; этанол $+\mathrm{AlCl}_{3}: 273,303,422$; этанол $+\mathrm{HCl}: 274,358,385$. Сравнивая полученные данные с таковыми аутентичных образцов и литературными данными [16], вещество Б мы идентифицировали как 5,7,3',4'-тетраоксифлавон (лютеолин).

Вещество В - светло-желтые кристаллы с $\mathrm{R}_{\mathrm{f}} 0,33$ (системах I) и 0,75 (система III). В УФ-спетре име-

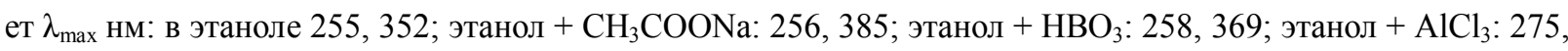
400; этанол + $\mathrm{HCl}: 275,390$ нм. При кислотном гидролизе образует агликон, который по $\mathrm{R}_{\mathrm{f}}$, окраске пятен на хроматограмме и УФ-спектру с комплексообразующими реагентами идентифицирован с лютеолином. 
Добавка ацетата натрия и борной кислоты к раствору гликозида не дает батохромный сдвиг полос, что указывает на присоединение сахарного остатка к агликону в положении $\mathrm{C}_{7}$. При кислотном гидролизе выход агликона составляет 66\%, что свидетельствует об его моногликозидной природе. Методом бумажной хроматографии в системах VII и VIII, в гидролизате после нейтрализации анионита обнаружили вещество, идентичное с D-глюкозой. На основании данных хроматографии, УФ спектров, результатов кислотного гидролиза вещество В идентифицировано как 5,3',4'-триокси-7-О- $\beta$ - D-глюкопиранозид (цинарозид).

Вещество Г - светло-желтый аморфный порошок (из 70\% этанола), хорошо растворимый в этаноле, метаноле, воде, слабо в ацетоне, не растворимый в хлороформе, эфире, $\mathrm{R}_{\mathrm{f}}$-значение 0,61 (в системе I), 0,20 (в системе II), УФ-спектре $\lambda_{\max }$ нм: в этаноле: $259,298,361$; этанол $+\mathrm{CH}_{3} \mathrm{COONa}$ : 270, 370; этанол $+\mathrm{H}_{3} \mathrm{BO}_{3}$ : 290,380 ; этанол $+\mathrm{C}_{2} \mathrm{H}_{5} \mathrm{ONa}: 280,410$; этанол $+\mathrm{AlCl}_{3}: 280,420$; этанол $+\mathrm{HCl}: 265,400$ нм. Батохромный сдвиг от хлористого алюминия и ацетата натрия указывает на присутствие свободной гидроксильной группы в положениях $\mathrm{C}_{5}$ и $\mathrm{C}_{7}$, смешение при добавлении ацетата натрия и борной кислоты указывает на нали-

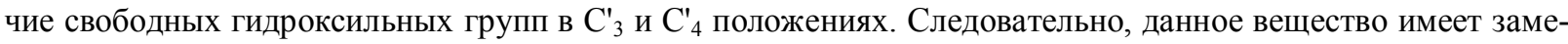
щенную гидроксильную группу в положении $\mathrm{C}_{3}$.

При кислотном гидролизе образуется агликон (64\%), что указывает на монозидную природу вещества. В углеводной части гидролизата на хроматограмме обнаружен сахар, тождественный с галактозой. По $\mathrm{R}_{\mathrm{f}}$-значению и результатам УФ-спектров с ионизирующими и комплексообразующими реагентами исследованное вещество идентично веществу А (кверцетин). Под действием фермента это вещество распадается на агликон и сахарный компонент, что указывает на $\beta$-конфигурацию гликозидной связи.

На основании данных хроматографии, кислотных и ферментативных гидролизов и сравнения их с литературными данными [16] вещество В идентифицировано как 5,7,3',4'-тетрагидроксифлавон-3-O- $\beta$-Dгалактозид (гиперин).

Вещество Д - желтый порошок, хорошо растворимый в этаноле, метаноле, не растворимый в хлороформе, эфире, гексане, т.пл. 229-230 ${ }^{\circ} \mathrm{C}, \mathrm{R}_{\mathrm{f}}$-значение 0,36 (в системе I), 0,68 (в системе V), УФ-спектре $\lambda_{\max }$ нм в этаноле: 270,364 . При гидролизе в гидролизате обнаружен агликон $(65 \%)$, который по данным щелочной деструкции и хроматографических сравнений, а также по данным УФ-спектров идентичен кверцетину (вещество А). В углеводной части гидролизата на хроматограмме обнаружен сахар, идентичный L-арабинозе. Согласно данным хроматографии, УФ-спектров, кислотного гидролиза, а также сравнением их с литературными данными вещество Г идентифицировано как 5,7,3',4'-тетрагидроксифуран-3-O- $\alpha$-Lарабинозид (авикулярин).

Изучение количественного содержания флавоноидов в надземных органах горца разнолистного показало, что оно изменяется в зависимости от местопроизрастания растения в пределах 1,44-2,12\% на воздушно-сухой вес сырья. Надземную часть растения можно использовать в качестве сырья для получения лекарственных препаратов флавоноидной природы с антиоксидантной и другими свойствами. Все данные для горца разнолистного получены впервые.

\section{Выводы}

1. Установлено, что спиртовый экстракт из надземной части P. heterophyllum содержит 11 веществ фенольной природы из которых 7 относятся к флавоноидам. Из суммы флавоноидов выделены 5 индивидуальных веществ и идентифицированы как кверцетин, лютеолин, гиперин, цинарозид и авикулярин.

2. Выявлено, что содержание флавоноидов в надземных органах горца разнолистного изменяется в зависимости от местопроизрастания в пределах 1,44-2,12\% на воздушно-сухой вес сырья.

\section{Список литературы}

1. Рзазаде Р.Я. Род Polygonum L. Флора Азербайджана. Баку, 1954. Т. III. С. 166.

2. Wu X.Q. General review on chemical constituent and pharmacological effects of Radix Polygoni multiflori // LiShiZhen Med. Mater. Med. Res. 2009. Vol. 20. Pp. 146-147.

3. Xiaoxv Dong, Jing Fu, Xingbin Yin, Xuechun Li, Bo Wang, Sali Cao1, Jin Zhang, Hui Zhang, Yang Zhao, Jian Ni. Pharmacological and other Bioactivities of the Genus Polygonum // A Review. Tropical Journal of Pharmaceutical Research. 2014. Vol. 13. N10. Pp.1749-1759

4. López S.N., Sierra M.G., Gattuso S.J., Furlàn R.L., Zacchino S.A. An unusual homoisoflavanone and a structurallyrelated dihydrochalcone from Polygonum ferrugineum (Polygonaceae) // Phytochemistry. 2006. N67. Pp. 2152-2158. 
5. Datta B.K., Rahman M.M., Gray A.I., Sayed A.H., Auzi A.A., Sarke S.D. Polygosumic acid, a new cadinane sesquiterpene from Polygonum viscosum, inhibits the growth of drug-resistant Escherichia coli and Staphylococcus aureus (MRSA) in-vitro // Journal of Natural Medicines. 2007. Vol. 61. Pp. 391-396.

6. Smolarz H.D., Potrzebowski M.J. Persilben - new carboxystilbene from Polygonum persicaria // J. Mol. Structure. 2002. Vol. 605. Pp.151-156

7. Qader S.W., Abdulla M.A., Chua L.S., Sirat H.M., Hamdan S. Pharmacological Mechanisms Underlying Gastro protective Activities of the Fractions Obtained from Polygonum minus in Sprague Dawley Rats // Int. J. Mol. Sci. 2012. Vol. 13. Pp. 1481-1496.

8. Kaul T.N., Middleton E. Jr., Ogra P.L. Antiviral effect of flavonoids on human viruses // J. Med. Virol. 1985. Vol. 15(1). Pp. 71-79.

9. Pandit S., Kim H.J., Park S.H., Jeon J.G. Enhancement of fluoride activity against Streptococcus mutans biofilms by a substance separated from Polygonum cuspidatum // Biofouling. 2012. Vol. 28. Pp. 279-287.

10. Hu B., An H.M., Shen K.P., Song H.Y., Deng S. Polygonum cuspidatum Extract Induces Anoikis in Hepatocarcinoma Cells Associated with Generation of Reactive Oxygen Species and Down regulation of Focal Adhesion Kinase // Evid-Based Compl. Alt. 2012. Pp. 1-9.

11. Kim H.N., Kim Y.R., Jang J.Y., Choi Y.W., Baek J.U., Hong J.W., Choi Y.H., Shin H.K., Choi B.T. Neuroprotective effects of Polygonum multiflorum extract against glutamateinduced ox-idative toxicity in HT22 hippocampal cells // J. Ethnopharmacol. 2013. Vol. 150. Pp. 108-115.

12. Cheong H., Ryu S.Y., Oak M.H., Cheon S.H., Yoo G.S., Kim K.M. Studies of structure activity relationship of flavonoids for the anti-allergic actions // Arch. Pharm. Res. 1998. Vol. 21(4). Pp.478-480.

13. Han J.H., Koh W., Lee H.J., Lee E.O., Lee S.J., Kim J.T., Khil J.H., Jeong S.J., Kim S.H. Analgesic and antiinflammatory effects of ethyl acetate fraction of Polygonum cuspidatum in experimental animals // Immunopharm. Immunot. 2012. Vol. 34. Pp. 191-195.

14. Jang H.G., Heo B.G., Park Y.S., Namiesnik J., Barasch D., Katrich E., Vearasilp K., Trakhtenberg S., Gorinstein S. Chemical Composition, Antioxidant and Anticancer Effects of the Seeds and Leaves of Indigo (Polygonum tinctorium Ait.) // Plant. Appl. Biochem. Biotechnol. 2012. Vol. 167. Pp. 1986-2004.

15. Mabry T.S., Markham R.K., Thomson M.B. The systematic identification of flavonoids. Springer-Verlaq. BerlinHeidelberg-New York, 1970. $151 \mathrm{p}$.

16. Andersen O.M., Kenneth R. Markham. Flavonoids: Chemistry, Biochemistry and Applications. CRC Press, 2005. $1256 \mathrm{p}$.

17. Хайс И.М., Мацех К. Хроматография на бумаге. М., 1962. 851 с.

18. Федосеева Г.М., Мирович В.М., Переломова М.В. Фитохимический анализ растительного сырья, содержащего флавоноиды. Методическое пособие по фармакогнозии. Иркутск, 2009. 67 с.

19. Bryant E.T. A note of the differentiation between flavonoid glycosides and their aglycones // J. Amer. Pharm. Assoc. 1950. Vol. 39. N8. Pp. 480-488.

Поступило в редакичию 26 июля 2016 г.

После переработки 28 октября 2016 г. 

LINDM.

Dzhafarova E.E. ${ }^{l *}$, Serkerov S.V. ${ }^{2}$, Mustafayeva L.A. ${ }^{2}$ FLAVONOIDS OF POLYGONUM HETEROPHYLLUM

${ }^{I}$ Institute of Genetic resources of NANA, pr. Azadlyg, 155, Baku, AZ1106 (Republic of Azerbaijan),

e-mail: eldar_novruzov@yahoo.co.uk

${ }^{2}$ Institute of Botany of NANA, Badamdarskoye shosse, 40, Baku, AZ1073 (Republic of Azerbaijan)

Species of the genus knotweed rich various biologically active substances - flavonoids, catechins, antrohoniny, stilbenes and others. Species of the genus knotweed characterized by high content of flavonoid compounds that have antioxidant, antimicrobial, antiviral, anti-allergic, anti-carcinogenic, anti-inflammatory properties. The quantitative content and quality of the aerial part of flavonoids of Polygonum heterophyllum was studied. By the method of two-dimensional paper chromatography revealed that the extract of the aerial parts of the plant contains 11 compounds of polyphenol nature, 7 substances give a characteristic reaction to flavonoids. By preparative paper chromatography allocated two substances, by column chromatography on polyamide 3 substances in individual condition, 2 of them are aglycones, 3 of them are glycosides. On the basis of chromatographic data, spectral analyzes aglycones identified as quercetin and luteolin. According to the results of chromatography, spectral analyzes and acid hydrolyses glycosides identified as luteolin-7-glucoside, quercetin-3-glucoside, quercetin-3-galactoside and quercetin-3-arabinoside. It was found that depending on the habitat of plant flavonoid content varies between 1,44-2,12\% on air-dry weight of raw materials.

Keywords: Polygonum heterophyllum, flavonoids, aerial part, chromatography, spectroscopy, hydrolysis.

\section{References}

1. Rzazade R.Ia. Pod Polygonum L. Flora Azerbaidzhana. [The genus Polygonum L. Flora of Azerbaijan]. Baku, 1954, vol. III, p. 166. (in Russ.).

2. Wu X.Q. LiShiZhen Med. Mater. Med. Res., 2009, vol. 20, pp. 146-147.

3. Xiaoxv Dong, Jing Fu, Xingbin Yin, Xuechun Li, Bo Wang, Sali Cao1, Jin Zhang, Hui Zhang, Yang Zhao, Jian Ni. A Review. Tropical Journal of Pharmaceutical Research, 2014, vol. 13, no. 10, pp.1749-1759.

4. López S.N., Sierra M.G., Gattuso S.J., Furlàn R.L., Zacchino S.A. Phytochemistry, 2006, no. 67, pp. $2152-2158$.

5. Datta B.K., Rahman M.M., Gray A.I., Sayed A.H., Auzi A.A., Sarke S.D. Journal of Natural Medicines, 2007, vol. 61, pp. 391-396.

6. Smolarz H.D., Potrzebowski M.J. J. Mol. Structure, 2002, vol. 605, pp.151-156

7. Qader S.W., Abdulla M.A., Chua L.S., Sirat H.M., Hamdan S. Int. J. Mol. Sci., 2012, vol. 13, pp. 1481-1496.

8. Kaul T.N., Middleton E. Jr., Ogra P.L. J. Med. Virol., 1985, vol. 15(1), pp. 71-79.

9. Pandit S., Kim H.J., Park S.H., Jeon J.G. Biofouling, 2012, vol. 28, pp. 279-287.

10. Hu B., An H.M., Shen K.P., Song H.Y., Deng S. Evid-Based Compl. Alt., 2012, pp. 1-9.

11. Kim H.N., Kim Y.R., Jang J.Y., Choi Y.W., Baek J.U., Hong J.W., Choi Y.H., Shin H.K., Choi B.T. J. Ethnopharmacol., 2013, vol. 150, pp. 108-115.

12. Cheong H., Ryu S.Y., Oak M.H., Cheon S.H., Yoo G.S., Kim K.M. Arch. Pharm. Res., 1998, vol. 21(4), pp.478-480.

13. Han J.H., Koh W., Lee H.J., Lee E.O., Lee S.J., Kim J.T., Khil J.H., Jeong S.J., Kim S.H. Immunopharm. Immunot., 2012, vol. 34, pp. 191-195.

14. Jang H.G., Heo B.G., Park Y.S., Namiesnik J., Barasch D., Katrich E., Vearasilp K., Trakhtenberg S., Gorinstein S. Plant. Appl. Biochem. Biotechnol., 2012, vol. 167, pp. 1986-2004.

15. Mabry T.S., Markham R.K., Thomson M.B. The systematic identification of flavonoids. Springer-Verlaq. BerlinHeidelberg-New York, 1970, $151 \mathrm{p}$.

16. Andersen O.M., Kenneth R. Markham. Flavonoids: Chemistry, Biochemistry and Applications. CRC Press, 2005, $1256 \mathrm{p}$.

17. Khais I.M., Matsekh K. Khromatografiia na bumage. [Chromatography on paper]. Moscow, 1962, 851 p. (in Russ.).

18. Fedoseeva G.M., Mirovich V.M., Perelomova M.V. Fitokhimicheskii analiz rastitel'nogo syr'ia, soderzhashche-go flavonoidy. Metodicheskoe posobie po farmakognozii. [Phytochemical analysis of plant material containing flavonoids. Toolkit Pharmacognosy]. Irkutsk, 2009, 67 p. (in Russ.).

19. Bryant E.T. J. Amer. Pharm. Assoc., 1950, vol. 39, no. 8, pp. 480-488.

Received July 26, 2016

Revised October 28, 2016

\footnotetext{
* Corresponding author.
} 
